\title{
The effect of volatiles on the measurement of the reaction heat by differential scanning calorimetry
}

Eduard García ${ }^{1,3}$, Daniel Sánchez-Rodríguez ${ }^{1}$, Joan Pere López-Olmedo ${ }^{2}$, Jordi Farjas ${ }^{1}$ and Pere Roura ${ }^{*}$.

${ }^{1}$ GRMT, Dept. of Physics, University of Girona, Campus Montilivi, Edif. PII, E17071 Girona, Catalonia, Spain

${ }^{2}$ UAT, Serveis Generals de Recerca, University of Girona, Campus Montilivi, Edif. PII, E17071 Girona, Catalonia, Spain

${ }^{3}$ Industrias Cerámicas Brancós, Migdia, s/n, E17100 La Bisbal, Catalonia, Spain

* corresponding author: pere.roura@ugd.cat, (34)972418383; Fax: (34)972418098

\begin{abstract}
When gases evolve during a chemical reaction, a fraction of the reaction heat is lost with them. We have analyzed, both theoretically and experimentally, the deviations that this effect can produce on the determination of the reaction heat by Differential Scanning Calorimetry (DSC). It is shown that, even in absence of gas overheating, deviations related to variations in the sample heat capacity can be substantial in experiments involving very intense DSC peaks. However, experiments performed on thermal decomposition of metalorganic salts and on evaporation of liquids have shown that deviations usually arise from gas overheating..
\end{abstract}

Keywords: DSC, reaction heat, boiling, decomposition, overheating, volatiles 


\section{List of symbols}

$\alpha \quad$ transformed fraction

$\beta \quad$ heating rate of the reference temperature

C heat capacity of the sample placed inside the pan

$\mathrm{C}_{\mathrm{A}}, \mathrm{C}_{\mathrm{B}}$ heat capacity of the solid sample at the beginning and at the end of the reaction

$\mathrm{C}_{\mathrm{G}}$ heat capacity of the evolved gas

$\mathrm{c}_{\mathrm{pS}}, \mathrm{c}_{\mathrm{pL}}, \mathrm{c}_{\mathrm{pG}}$ specific heat capacity (per unit mass) at constant pressure of solid, liquid and gas

$\mathrm{C}_{\mathrm{REF}}$ pan heat capacity

$\mathrm{DSC}_{\mathrm{P}}$ DSC value after baseline subtraction

$\Delta \mathrm{H} \quad$ enthalpy of reaction

$\Delta \mathrm{T}_{\mathrm{G}} \quad$ gas overheating above $\mathrm{T}_{\mathrm{S}}$

$\Delta \mathrm{Q}_{\mathrm{C}}, \Delta \mathrm{Q}_{\mathrm{G}}, \Delta \mathrm{Q}_{\mathrm{P}} \quad$ corrections to the measured heat due to gas evolution (see main text)

$\mathrm{L}_{\mathrm{BOIL}}$ latent heat of boiling

$\mathrm{L}_{\mathrm{EV}}$ latent heat of evaporation

$\mathrm{m}$ mass of the sample remaining inside the pan

Q DSC peak area (after baseline subtraction)

$\dot{q} \quad$ heat power exchanged due to a chemical reaction $\left(\Delta H=\int \dot{q} d t\right)$

$\dot{Q}_{R E F}$ heat power flowing through the "sample" side of the DSC sensor

$\dot{Q}_{S} \quad$ idem through the "reference" side

$\mathrm{R}$ thermal resistance of the DSC sensor

$\mathrm{T}_{\mathrm{BOIL}}$ boiling point

$\mathrm{T}_{\mathrm{REF}}$ temperature at the "reference" side of the DSC sensor

$\mathrm{T}_{\mathrm{S}} \quad$ temperature at the "sample" side of the DSC sensor

$\tau_{\text {SIGNAL }} \quad$ time constant characteristic of the DSC signal

\section{Introduction}

Many structural transformations of materials involve reaction with a gas or evolution of gaseous species. To give a few common examples, this is the case of metal oxidation, thermal degradation of polymers and thermal decomposition of metal sulfates, carbonates or oxides. Accurate measurement of the heat of reaction by calorimetry may be limited if the heat exchanged with the gas cannot be controlled. Probably, this is the reason why alternative methods are used when possible. For instance, the latent heat of evaporation or the heat of 
carbonate decomposition are usually obtained from the temperature dependence of the equilibrium vapor pressure through application of the Clausius-Clapeyron equation [1].

We have recently studied very exothermic reactions of metal-organic compounds [2].Since these compounds lose a significant part of their mass when transformed into metal oxides, we wonder if the reaction heat delivered by Differential Scanning Calorimetry (DSC) is accurate enough. The reason of our doubts can be explained as follows. A heat-flux DSC delivers the heat power flowing from the sample to the furnace (F) "due to the transformations that take place in the sample" by measuring the temperature difference between the "sample" (S) and the "reference" (REF) thermocouple contacts (Fig.1) [3], i.e.

$$
D S C \equiv \dot{Q}_{S}-\dot{Q}_{R E F}=\frac{T_{S}-T_{R E F}}{R},
$$

where the heat power flowing at the reference side,

$$
\dot{Q}_{R E F}=\frac{T_{R E F}-T_{F}}{R},
$$

has been subtracted from that flowing at the sample side,

$$
\dot{Q}_{S}=\frac{T_{S}-T_{F}}{R}
$$

and $R$ is the thermal resistance of the DSC sensor (usually a ceramic disc). So, during an exothermic reaction ( $\mathrm{DSC}>0$ ), due to $R$, the sample is overheated with respect to the reference pan. When the same mass is large enough, additional overheating occurs due to heat transport through the sample itself [4] and it reaches a maximum value when exothermic reactions proceed via a combustion process [2]. When the reaction takes place in a condensed state (solid or liquid) the heat entirely flows through the DSC sensor. However, if gas evolves, part of the heat escapes with the overheated gas and it is not measured by the apparatus. Consequently, the measured reaction heat will be lower than the real value. The aim of this paper is to analyze this effect both theoretically and experimentally. We will see that additional deviations appear even if heat does not escape with the gas. These deviations are related to variations in the heat capacity of the sample.

\section{Theoretical analysis}

Consider the chemical reaction:

$$
\mathrm{A}--->\mathrm{B}+\mathrm{G} \uparrow \text {, }
$$

where $\mathrm{A}$ and $\mathrm{B}$ are condensed species and $\mathrm{G}$ is a volatile. The heat capacity of the material contained in the sample pan, $\mathrm{C}$, will change during the reaction according to:

$$
C=\alpha C_{B}+(1-\alpha) C_{A},
$$


where $\alpha$ is the transformed fraction (i.e. $\alpha$ changes from 0 to 1 as the reaction proceeds). For a simple reaction like that of Eq.4, $\alpha$ can be determined from the sample mass, $m$, measured by thermogravimetry:

$$
\alpha(t) \equiv \frac{m_{A}-m(t)}{m_{A}-m_{B}} .
$$

If the time constant of the DSC signal is short enough, $\alpha$ can also be obtained from the DSC peak area:

$$
\frac{d \alpha}{d t}=\frac{D S C_{P}}{Q}
$$

where subindex "P" refers to the DSC peak once the baseline due to the variation of C has been subtracted (Fig.2) and Q is the peak area. This subtraction is necessary when experiments are done at a constant heating rate,

$$
\beta \equiv \frac{d T_{R E F}}{d t}
$$

and must be performed iteratively $[3,5]$.

Once $\mathrm{C}$ is known, the relationship between the DSC signal and the power related to the chemical reaction $\dot{q}$ can be deduced. The energy balance at the sample side of the DSC sensor can be written as:

$$
\dot{q} d t=\dot{Q}_{S} d t+\left(C_{R E F}+C\right) d T_{S}-c_{p G} d m \Delta T_{G},
$$

i.e. the heat evolved during a time interval $d t$ will flow through the DSC sensor $\left(\dot{Q}_{S}\right)$, will increase the sample and pan temperature $\left(\mathrm{dT}_{\mathrm{S}}\right)$, and will escape with the gas, overheated by the amount $\Delta \mathrm{T}_{\mathrm{G}}\left(\mathrm{c}_{\mathrm{pG}}\right.$ is the gas specific heat at constant pressure and $d m$, the sample mass loss). This overheating is referred to the temperature of the solid sample, $\mathrm{T}_{\mathrm{S}}$, i.e. $\Delta T_{G} \equiv T_{G}-$ $T_{S}$.

Eq.9 can be transformed to contain the DSC signal. From Eqs.1-3, we obtain:

$$
\dot{q}=D S C+C \beta+R\left(C_{R E F}+C\right) \frac{d D S C}{d t}+c_{p G}\left(\frac{-d m}{d t}\right) \Delta T_{G} .
$$

Since $-C \beta$ is the baseline due to heat capacity variation, $D S C+C \beta$ is just the value of the DSC peak after baseline subtraction ( $\mathrm{DSC}_{\mathrm{P}}$ in Fig. 2). Consequently, time integration of Eq.10 from the beginning to the end of the reaction leads to:

$$
-\Delta H \equiv Q+\Delta Q
$$

i.e., in general, the measured reaction heat, $\mathrm{Q}$, will not coincide with the actual value $(\Delta \mathrm{H}$ is the reaction enthalpy).

In the following, we will see that $\Delta \mathrm{Q}$ has three contributions,

$$
\Delta Q=\Delta Q_{C}+\Delta Q_{P}+\Delta Q_{G} .
$$


$\Delta \mathrm{Q}_{\mathrm{C}}$ exclusively depends on the variation in the heat capacity of the sample inside the pan. Its value is independent of the reaction heat. $\Delta \mathrm{Q}_{\mathrm{P}}$ is related to the sample overheating with respect to the reference pan that arises from the reaction heat (i.e. the DSC peak) flowing through the thermal resistance. Although the sample and its pan are overheated, they share the same temperature that is equal to $\mathrm{T}_{\mathrm{S}}$. Both $\Delta \mathrm{Q}_{\mathrm{C}}$ and $\Delta \mathrm{Q}_{\mathrm{P}}$ are indirectly related to the gas evolution because they are proportional to the variation of $\mathrm{C}$ that will be usually high when gas evolves. However, these contributions would be non-zero even in solid-solid reactions. Consequently, they cannot be interpreted as heat that is transported away from the sensor by the gas. Finally, $\Delta \mathrm{Q}_{\mathrm{G}}$ is due to the gas overheating with respect to the sample $\left(\mathrm{T}_{\mathrm{G}}>\mathrm{T}_{\mathrm{S}}\right)$. This contribution quantifies the heat that is directly transported away by the gas. Although differences between $\mathrm{Q}$ and $-\Delta \mathrm{H}$ arise in any reaction because of the heat capacity variation, $\Delta \mathrm{Q}$ will be only significant if gases are involved due to higher variation in heat capacity $\left(\Delta \mathrm{Q}_{\mathrm{C}}+\Delta \mathrm{Q}_{\mathrm{P}}\right)$ and to the eventual gas overheating $\left(\Delta \mathrm{Q}_{\mathrm{G}}\right)$.

In the Appendix, $\Delta \mathrm{Q}_{\mathrm{C}}$ and $\Delta \mathrm{Q}_{\mathrm{P}}$ are deduced assuming that no temperature gradients occur within the sample. For, $\Delta \mathrm{Q}_{\mathrm{C}}$ we obtain:

$$
\Delta Q_{C}<\tau_{\text {SIGNAL }}\left(C_{A}-C_{B}\right) \beta,
$$

where $\tau_{\text {SIGNAL }}$ is a time constant characteristic of the DSC sensor whose value is close to the decay time of the melting peak of pure metals (Fig. 3) and the sign $<$ holds for reactions involving gas evolution. Eq.13 tells us that $\Delta \mathrm{Q}_{\mathrm{C}}$ is independent of the reaction heat. In contrast, $\Delta \mathrm{Q}_{\mathrm{P}}$ depends on $\mathrm{Q}$ in a cumbersome way,

$$
\Delta Q_{P}=\frac{R\left(C_{A}-C_{B}\right)}{Q} \int D S C \cdot D S C_{P} d t,
$$

because the DSC signal also scales with Q. Since the sign of the integration will always be positive, $\Delta \mathrm{Q}_{\mathrm{P}}$ and $\mathrm{Q}$ will have the same sign for a reaction that involves a gas product $\left(C_{A}-C_{B}>0\right)$. Consequently, this term will reduce the measured reaction heat either in exothermic or endothermic reactions. Finally, $\Delta \mathrm{Q}_{\mathrm{G}}$ can be written as:

$$
\Delta Q_{G} \cong C_{G} \cdot \overline{\Delta T_{G}},
$$

where $\mathrm{C}_{\mathrm{G}}$ is the heat capacity of the evolved gas and $\overline{\Delta T_{G}}$ is the average gas overheating. If the gas is thermalized with the sample, $\Delta \mathrm{Q}_{\mathrm{G}}$ will be zero because, in this case, $\Delta \mathrm{T}_{\mathrm{G}}=0$.

\section{Experimental details}

Calorimetric experiments were done with the DSC822 by Mettler Toledo. The DSC signal was calibrated by melting high purity In and Zn references (Fig.3). From the slope of the lowtemperature side of the melting peaks the thermal resistance of the DSC sensor plus the 
contact resistance between the pan and the sensor, $R$, has been obtained. It depends on the furnace atmosphere and the pan. For aluminum pans in $\mathrm{N}_{2}$ atmosphere, $\mathrm{R}$ varies from 140 ${ }^{\circ} \mathrm{C} / \mathrm{W}$ at $160^{\circ} \mathrm{C}$ to $240{ }^{\circ} \mathrm{C} / \mathrm{W}$ at $420^{\circ} \mathrm{C}$. The high-temperature side of the melting peaks decays exponentially with a time constant, $\tau_{\mathrm{SIGNAL}}$, about $5 \mathrm{~s}$ long.

The samples were placed inside aluminum crucibles with or without sealed covers where we made a hole to allow gases to escape. Experiments were done at a constant heating rate and in an inert atmosphere of nitrogen. When necessary, a second DSC curve was used to define the apparatus baseline.

\section{Results and discussion}

\section{a) Thermal decomposition of Yttrium trifluoracetate [Y(TFA $\left.)_{3}\right]$}

Thin films and powders of metal oxides are currently obtained by thermal decomposition of metal organic precursor salts [6]. The organic part of the molecule (organic ligands) evolves and leaves behind the oxide as a solid residue. The gaseous species and the heat of decomposition usually depend on the furnace atmosphere because of the partial oxidation of the organic ligands. In most cases, the degree of oxidation depends on the particular experimental conditions (sample mass, heating rate, air flow rate...) making it difficult to experimentally assess how much heat is lost with the volatiles [7].

$\mathrm{Y}(\mathrm{TFA})_{3}$ is a precursor salt of $\mathrm{Y}_{2} \mathrm{O}_{3}$ that decomposes into $\mathrm{YF}_{3}$ as an intermediate product. The $\mathrm{Y}(\mathrm{TFA})_{3}$ decomposition is exothermic even in inert atmosphere where volatiles do not oxidize [8]. Consequently, if the reaction heat varies at different experimental conditions, we can be sure that this is due to the heat lost with the volatiles. In addition, in the form of powders, $\mathrm{Y}(\mathrm{TFA})_{3}$ decomposes through a combustion process that entails very high and narrow DSC peaks [2] making the value of the integral of Eq.14 large enough to be able to measure $\Delta \mathrm{Q}_{\mathrm{P}}$ even for small amounts of sample.

In a first series of experiments, $\mathrm{Y}(\mathrm{TFA})_{3}$ powders (initial mass $\mathrm{m}_{\mathrm{i}}=1,2,5$ and $8 \mathrm{mg}$, approx.) were heated in $\mathrm{N}_{2}$ inside sealed aluminum pans with a pinhole on their cover to facilitate thermalization of the volatiles with the pan before they leave it. The DSC peak measured with $\mathrm{m}_{\mathrm{i}}=5 \mathrm{mg}$ is shown in Fig. 4 (solid curve). In Fig. 5 (full symbols), we observe that $\mathrm{Q} / \mathrm{m}_{\mathrm{i}}$ steadily diminishes with increasing $\mathrm{m}_{\mathrm{i}}$. This variation (of about $80 \mathrm{~J} / \mathrm{g}$ along the whole mass range) will be now compared with the value expected from Eqs.13 and $14\left(\Delta \mathrm{Q}_{\mathrm{C}}\right.$ and $\left.\Delta \mathrm{Q}_{\mathrm{P}}\right)$. 
At the peak temperature, $R=205^{\circ} \mathrm{C} / \mathrm{W}$, and a reliable value for $\left(\mathrm{C}_{\mathrm{B}}-\mathrm{C}_{\mathrm{A}}\right) / \mathrm{m}_{\mathrm{i}}$ of 1.1-1.2 $\mathrm{J} / \mathrm{g} /{ }^{\circ} \mathrm{C}$ has been obtained from the shift of the DSC signal after the peak for the largest three masses. Application of Eq. 13 with $\tau_{\mathrm{SIGNAL}}=5 \mathrm{~s}$ and $\beta=20{ }^{\circ} \mathrm{C} / \mathrm{min}$ delivers $\Delta \mathrm{Q}_{\mathrm{C}} / \mathrm{m}_{\mathrm{i}}=1.8 \mathrm{~J} / \mathrm{g}$. This value is negligible when compared with the measured reaction heat $\left(\mathrm{Q} / \mathrm{m}_{\mathrm{i}}>220 \mathrm{~J} / \mathrm{g}\right)$ and cannot explain the experimental variation of $\mathrm{Q} / \mathrm{m}_{\mathrm{i}}$ because $\Delta \mathrm{Q}_{\mathrm{C}} / \mathrm{m}_{\mathrm{i}}$ does not depend on $\mathrm{m}_{\mathrm{i}}$.

$\Delta \mathrm{Q}_{\mathrm{P}}$ has been calculated through integration of the DSC peak according to Eq.14. The values thus obtained are plotted in the inset of Fig. 4. They predict a steady diminution of $\mathrm{Q} / \mathrm{m}_{\mathrm{i}}$ with $\mathrm{m}_{\mathrm{i}}$, which is indeed observed. However, the maximum predicted heat lost by the volatiles $(22 \mathrm{~J} / \mathrm{g})$ is much smaller than the observed experimental variation of $\mathrm{Q} / \mathrm{m}_{\mathrm{i}}(80 \mathrm{~J} / \mathrm{g})$, this discrepancy being beyond the experimental uncertainty.

We are let to consider that, despite the experimental precautions, the evolving species do not thermalize with the pan but on the contrary they leave it at a much higher temperature. So, the evolution of $\mathrm{Q} / \mathrm{m}_{\mathrm{i}}$ with the mass is probably due to gas overheating. The problem, now, is that $\Delta \mathrm{Q}_{\mathrm{G}}$ (Eq.15) cannot be predicted if $\overline{\Delta T_{G}}$ is unknown. However, we can try to evaluate the heat lost through the overheated gas by doing experiments with improved gas thermalization.

To this aim, a second series of experiments was done. Now, the Y(TFA) 3 powders were covered by $20 \mathrm{mg}$ of alumina powders. Thermalization was thus improved because volatiles now flowed through the alumina powders before reaching the pinhole. The result on the DSC peak is spectacular, its area being more than twice larger than in the previous experiments (Fig. 4). This is to say that $3 / 4$ of the decomposition heat missed the DSC sensor and escaped with the volatiles. To get an idea of the gas overheating in the first series of experiments, we can divide the heat missed $(\approx 600 \mathrm{~J} / \mathrm{g} \cdot 5 \mathrm{mg})$ by an estimation of the gas heat capacity $\left(\mathrm{C}_{\mathrm{G}} \approx \mathrm{C}_{\mathrm{A}}-\mathrm{C}_{\mathrm{B}} \approx 1 \mathrm{~J} / \mathrm{g} /{ }^{\circ} \mathrm{C} \cdot 5 \mathrm{mg}\right)$. The result of several hundreds of Celsius agrees with the fact that, as said above, $\mathrm{Y}(\mathrm{TFA})_{3}$ decomposes via a combustion mechanism that entails the formation of a reaction front where conditions are quasiadiabatic, and that volatiles arise from this narrow hot region of the sample [2].

Since the DSC baseline of this second series of experiments was much less flat than that of the first series, Q could be determined with much lower accuracy. In fact, within experimental accuracy, no variation of $\mathrm{Q}$ with $\mathrm{m}_{\mathrm{i}}$ can be assessed from the experimental points (Fig. 5), and the heat transported away by the volatiles predicted by Eq.14 ( $\Delta \mathrm{Q}_{\mathrm{P}}$, inset of Fig. 4) remains hidden within the error bars. 
To conclude this section, we can say that, once the heat losses through the volatiles have been reduced to a minimum, the decomposition heat of $\mathrm{Y}(\mathrm{TFA})_{3}$ has been determined to be $850 \pm 50 \mathrm{~J} / \mathrm{g})$, this value being much higher than previously reported $(260 \pm 30 \mathrm{~J} / \mathrm{g}[8])$. This example shows that care must be taken to measure the decomposition heat of those metal organic salts that decompose via a combustion process.

\section{b) Overview of metal organic decomposition processes}

After avoiding gas overheating, we have not been able to measure DSC curves reliable enough to reveal the effect of $\Delta \mathrm{Q}_{\mathrm{C}}$ and $\Delta \mathrm{Q}_{\mathrm{P}}$ on $\mathrm{Q}$ for the particular example of $\mathrm{Y}(\mathrm{TFA})_{3}$. Now we want to analyze if $\Delta \mathrm{Q}_{\mathrm{C}}$ and $\Delta \mathrm{Q}_{\mathrm{P}}$ can be large enough for the ensemble of metal organic decomposition reactions to led to significant errors in the determination of their reaction heat.

A rough calculation of $\Delta Q_{P}$ can be done by substituting the real DSC peak by a rectangular pulse function with the same area and whose width, $\Delta \mathrm{t}$, coincides with the full width at half maximum (FWHM) of the DSC peak (Fig.2). Application of eq.14 gives:

$$
\frac{\Delta Q_{P}}{Q} \cong \frac{R\left(C_{A}-C_{B}\right)}{\Delta t}=R \cdot \frac{C_{A}-C_{B}}{Q} \frac{Q}{\Delta t},
$$

that allows to predict the experimental parameters that will have an influence on the heat losses (use of a triangular instead of a rectangular function adds a $2 / 3$ factor to the result). According to the right-hand side formula, the heat loss relative to the heat measured will depend on three terms:

a) the DSC apparatus through its thermal resistance. As $R$ gets larger, sample overheating will be higher for a given heat flow (Eq.1).

b) the reaction itself. The term $\left(C_{A}-C_{B}\right) / Q$ is nearly mass independent and tells us that even low enthalpic reactions may be effected by the gas species.

c) the particular experimental conditions through $\mathrm{Q} / \Delta \mathrm{t}$, i.e., the DSC peak intensity. This value increases with the sample mass and with the heating rate.

Let us apply Eq.16 to the decomposition of metal organic salts. Our own experiments with these substances give a range of $\mathrm{Q} / \mathrm{m}_{\mathrm{i}}$ values of $10^{2}-10^{4} \mathrm{~J} / \mathrm{g}[2,7,9]$. On the other hand, consider a typical variation of the specific heat, $\left(\mathrm{C}_{\mathrm{A}}-\mathrm{C}_{\mathrm{B}}\right) / \mathrm{m}_{\mathrm{i}}$, of $1 \mathrm{~J} / \mathrm{g} /{ }^{\circ} \mathrm{C}$. Since DSC peak intensities of $\mathrm{Q} / \Delta \mathrm{t}=50 \mathrm{~mW}$ are large enough to quantify the reaction heat application of Eq.16 with $\mathrm{R}=200{ }^{\circ} \mathrm{C} / \mathrm{W}$ delivers $\Delta \mathrm{Q}_{\mathrm{P}} / \mathrm{Q}$ in the $0.001-0.1$ range. This means that, without gas overheating, the measured reaction heat will be lowered, at most, by $10 \%$. For most experiments, this correction will be below the accuracy in the determination of the DSC peak 
area. Concerning $\Delta \mathrm{Q}_{\mathrm{C}} / \mathrm{Q}$ (Eq.13), for a typical heating rate of $\beta=20^{\circ} \mathrm{C} / \mathrm{min}$ and $\tau_{\mathrm{SIGNAL}}=5 \mathrm{~s}$, this correction will be in the 0.0002-0.02 range. It is clear that, unless very high heating rates are used, $\Delta \mathrm{Q}_{\mathrm{C}}$ will be much lower than $\Delta \mathrm{Q}_{\mathrm{P}}$. So $\Delta \mathrm{Q}_{\mathrm{C}}$ will not be considered for the rest of the paper.

\section{c) Evaporation of several liquids}

In the search for reactions that could reveal deviations between the reaction enthalpy and the heat measured by a DSC, we have analyzed the evaporation of several liquids. In principle, evaporation could reveal the non-trivial $\Delta Q_{P}$ term because vapor is expected to be thermalized with the liquid. Since no residue is left behind, $\mathrm{C}_{\mathrm{B}}=0$, the most suitable liquids will be those giving maximum $\mathrm{C}_{\mathrm{A}} / \mathrm{Q}$ values; that is, those with maximum $\mathrm{c}_{\mathrm{pL}} / \mathrm{L}_{\mathrm{BOIL}}$ ratios $\left(\mathrm{c}_{\mathrm{pL}}\right.$ and $\mathrm{L}_{\mathrm{BOIL}}$ are the specific heat capacity of the liquid and the boiling latent heat, respectively). A literature search has revealed that saturated hydrocarbons are among those liquids with the highest ratio (see Table 1). From the particular case of decane, and considering that in our DSC the signal saturates at $\pm 200 \mathrm{~mW}$, we expect $\Delta \mathrm{Q}_{\mathrm{P}} / \mathrm{Q}$ to be as high as $30 \%$ for a large enough amount of liquid; a deviation that can be easily measured.

In Figs. 6 and 7 we have plotted the DSC curves measured during evaporation of ethylbenzene and decane, respectively. The dotted lines correspond to the contribution of the liquid heat capacity to the DSC signal $\left(-\mathrm{m}(\mathrm{t}) \cdot \mathrm{c}_{\mathrm{pL}} \cdot \beta\right)$ that have been iteratively calculated with the $c_{p L}$ values given in Table 1. At first, the experiments were done with uncovered pans. The evaporation heats measured for ethylbenzene and decane were -130 and $-319 \mathrm{~J} / \mathrm{g}$ higher (40 and $140 \%$ ), respectively, than the expected $\mathrm{L}_{\mathrm{BOIL}}$ values (Table 1); these deviations being opposite in sign to those of $\Delta \mathrm{Q}_{\mathrm{P}}\left(\Delta \mathrm{Q}_{\mathrm{P}}\right.$ values are given in Figs.6 and 7).

Since evaporation takes place below the boiling point, the latent heat of evaporation, $\mathrm{L}_{\mathrm{EV}}(\mathrm{T})$, will differ from $\mathrm{L}_{\mathrm{BOIL}}$ because of the different specific heat capacity of vapor, $\mathrm{c}_{\mathrm{pG}}$, and liquid, according to:

$$
L_{E V}(T)=L_{B O I L}+\int_{T}^{T_{B O I L}}\left(c_{p L}-c_{p G}\right) d T \quad .
$$

For decane, $\mathrm{c}_{\mathrm{pG}}$ increases from $2.1 \mathrm{~J} / \mathrm{g} /{ }^{\circ} \mathrm{C}$ at the DSC peak temperature $\left(130^{\circ} \mathrm{C}\right)$ to $2.3 \mathrm{~J} / \mathrm{g} /{ }^{\circ} \mathrm{C}$ at $\mathrm{T}_{\mathrm{BOIL}}$. These values being very close to $c_{\mathrm{pL}}$, we estimate that $\mathrm{L}_{\mathrm{EV}}(\mathrm{T})-\mathrm{L}_{\mathrm{BOIL}}$ will be lower than $20 \mathrm{~J} / \mathrm{g}$. Consequently, the observed discrepancies between the measured heat of evaporation and $\mathrm{L}_{\mathrm{BOIL}}$ cannot be explained in terms of the temperature dependence of the latent heat. 
In our DSC experiments, evaporation takes place out of equilibrium and the molecules with highest probability to leave the liquid are those with higher energy. Consequently, the molecules in the vapor will have an average energy higher than that corresponding to the liquid temperature, as if the vapor was overheated. Application of Eq.17 indicates that, with the uncovered pans, the vapor is overheated by about 200 and 80 Celsius in decane and ethylbenzene, respectively.

Gas overheating can be reduced if heat exchange with the pan is improved. This can be easily done using covers sealed to the pan. In a second series of experiments, two covers with small pinholes were sealed to the pan. This simple modification has resulted, as expected, in a clear reduction of the heat needed for the evaporation of both ethylbenzene and decane (Figs. 6 and 7). Finally, we measured the evaporation with very tiny holes on the cover. The results were sharp evaporation peaks with onset temperatures slightly higher than the boiling point $\left(+3.5\right.$ and $\left.+2^{\circ} \mathrm{C}\right)$. Concerning the evaporation heat, it almost matched $\mathrm{L}_{\mathrm{BO}}$ for ethylbenzene but still remained much higher for decane.

The evolution of the evaporation peaks shown in Figs.6 and 7 with the cover condition has already been reported in the literature $[10,11,12]$ and led to propose the Standard Test Method for Determining Vapor Pressure by Thermal Analysis (ASTM E 178203) that entails the use of sealed crucibles with a small pinhole. With this method the boiling point can be determined from the peak onset with good accuracy (similar to ours [10]). However, it is not a standard for the measurement of $\mathrm{L}_{\mathrm{BOIL}}$. Although we do not know the reason, this fact may indicate the difficulty of measuring $\mathrm{L}_{\mathrm{BOIL}}$ from the DSC peak area.

To conclude this section we can say that, similarly to $\mathrm{Y}(\mathrm{TFA})_{3}$ combustion, gas overheating occurs during evaporation, although in this case it is and endothermic process.

\section{Summary and conclusions}

We have analyzed the effect that the gases involved in a reaction have on the measurement of the reaction heat by DSC. It has been shown that, in general, the measured value, Q, will differ from the reaction enthalpy by an amount, $\Delta Q$, which can be decomposed into three contributions. Two of them are related to the variation of the sample heat capacity. Their value, although negligible in most cases, is nonzero even when volatiles are thermalized with the sample. The third contribution is just the heat that escapes when the gas is overheated.

Thermal decomposition of metalorganic salts has shown that gas overheating can lead to very erroneous values of the reaction heat, especially when combustion takes place. So, 
care must be taken to ensure gas thermalization. It has been shown that, when thermalization is ensured, the experimental reaction heat will seldom differ by more than $10 \%$ from the actual value. In contrast, this deviation can be as high as $30 \%$ for the evaporation of those gases with high heat capacity/boiling latent heat ratio. Experiments with decane and ethylbenzene have delivered unexpected high evaporation heat values indicating that, although evaporation is an endothermic process, the vapor is overheated. We have interpreted this result as being due to the non-equilibrium conditions during evaporation below the boiling point because the molecules in the liquid with higher energy have a higher probability to escape to the vapor phase.

We conclude that: a) the errors on the measured reaction heat related to heat capacity variation can be calculated from the DSC curve and will usually be negligible, and b) gas overheating can lead to important errors that cannot be calculated from the DSC curve but they must be deduced from experiments controlling gas thermalization.

\section{Acknowledgements}

This work was partially funded by the Spanish Programa Nacional de Materiales through projects MAT2011-28874-C02-02 and by the Generalitat de Catalunya contract No. 2009SGR-185. The authors thank the University of Girona for the PhD fellowship granted to Daniel Sánchez-Rodríguez and for the use of the thermal analysis facilities (Serveis Tècnics de Recerca).

\section{Appendix: calculation of $\Delta Q_{P}$ and $\Delta Q_{C}$}

We need to calculate the third term on the right-hand side of Eq.10:

$$
\Delta Q_{C}+\Delta Q_{P}=R \int\left(C_{R E F}-C\right) d D S C .
$$

Integration by parts and substitution of $C$ by its value of Eq.5 leads to:

$\Delta Q_{C}+\Delta Q_{P}=R\left(C_{R E F}+C_{B}\right) D S C_{f}-R\left(C_{R E F}+C_{A}\right) D S C_{i}+R\left(C_{A}-C_{B}\right) \int D S C \frac{d \alpha}{d t} d t$,

where "i" and " $\mathrm{f}$ " refer to the value before and after the DSC peak.

$\Delta \mathrm{Q}_{\mathrm{C}}$ is the addition of the first two terms. If take into account that

$$
D S C_{f, i}=-\left(C_{R E F}+C_{B, A}\right) \beta,
$$

and consider that, usually,

$$
C_{R E F}+C_{B} \cong C_{R E F}+C_{A},
$$

we arrive to the desired result:

$$
\Delta Q_{C} \cong R\left(C_{R E F}+C_{A}\right)\left(C_{A}-C_{B}\right) \beta,
$$


where $R\left(C_{R E F}+C_{A}\right)$ is the DSC time constant $\tau_{\mathrm{SIGNAL}}[3]$ at the beginning of the reaction. For reactions involving gas evolution, $\mathrm{R}\left(\mathrm{C}_{\mathrm{REF}}+\mathrm{C}_{\mathrm{A}}\right)>\tau_{\mathrm{SIGNAL}}$.

The last term in Eq.A2 is $\Delta$ Qp. In general, $\alpha$ can be obtained from a TG curve (Eq.6). In those cases where the time response of the DSC signal is short enough, use of Eq. 7 leads to the desired result:

$$
\Delta Q_{P}=\frac{R\left(C_{A}-C_{B}\right)}{Q} \int D S C \cdot D S C_{P} d t
$$




\section{References}

[1] Zemansky MW. and Dittman RH., Heat and thermodynamics, Ch. 10, $6^{\text {th }}$ Edition, New York: McGraw-Hill, 1981.

[2] Sanchez-Rodriguez D, Farjas J, Roura P, Ricart S, Mestres N, Obradors X, Puig T, Thermal analysis for low temperature synthesis of oxide thin films from chemical solutions. J.Phys.Chem.C 2013; 117: 20133-20138.

[3] HöhneGWH,Hemminger W and Flammersheim H-J., Differential scanning calorimetry: an introduction for practitioners, Berlin: Springer-Verlag, 1996.

[4] Sanchez-Rodriguez D, Eloussifi H, Farjas J, Roura P, Dammak M, Thermal gradients in thermal analysis experiments: criterions to prevent inaccuracies when determining sample temperature and kinetic parameters, Thermochim. Acta 2014; 589: 37-46.

[5] Roduit B, Xia L, Folly P, Berger B, Mathieu J, Sarbach A, Andres H, Ramin M, Vogelsanger B, Spitzer D, Moulard H, Dilhan D. The simulation of the thermal behavior of energetic materials based on DSC and HFC signals. J Therm Anal Calorim. 2008;93:143-52.

[6] Schwartz R, Schneller T, Waser R, Chemical solution deposition of electronic oxide films. C. R. Chimie 2004; 7: 433-461.

[7] Roura P, Farjas J, Camps J, Ricart S, Arbiol J, Puig T, Obradors X. Decomposition processes and structural transformations of cerium propionate into nanocrystalline ceria at different oxygen partial pressures, J. Nanopart. Res. 2011; 13: 4085-4096.

[8] Eloussifi H, Farjas J, Roura P, Camps J, Dammak M, Ricart S, Puig T, Obradors X. Evolution of Yttrium trifluoroacetate during thermal decomposition, J.Therm. Anal. Calorim. 2012; 108: 589-596.

[9] Farjas J, Camps J, Roura P, Ricart S, Puig T, Obradors X, The thermal decomposition of barium trifluoroacetate, Thermochim. Acta 2012; 544: 77-83.

[10] Butrow AB, Seyler RJ, Vapor pressure by DSC: extending ASTM E 1782 below $5 \mathrm{kPa}$, Thermochim. Acta 2003; 402: 145-152.

[11] Contreras MD, Girela F, Parera A, The perfection of a method for the determination of the temperature vapor-pressure function of liquids by differential scanning calorimetry, Thermochimica Acta, 1993; 219: 167-172.

[12] Cedeño FO, Prieto MM, Espina A, Garcia JR, Fast method for the experimental determination of vaporization enthalpy by differential scanning calorimetry, J.Therm.Anal.Calorim. 2003; 73: 775-781. 


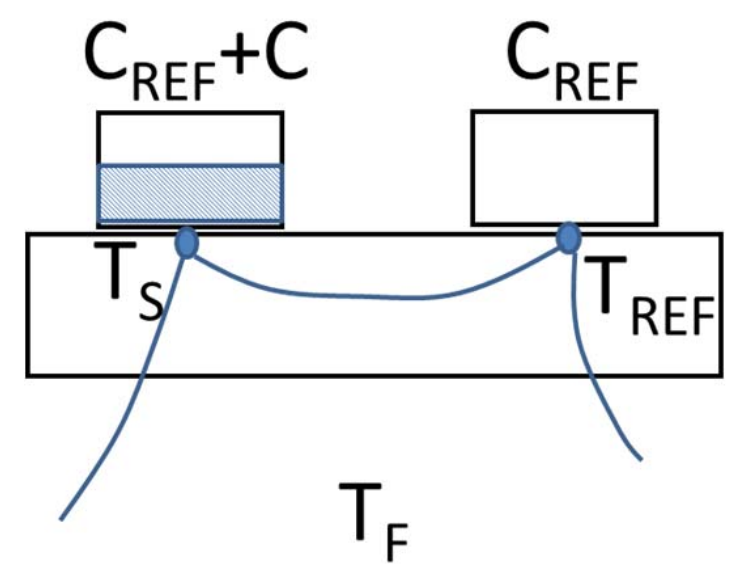

Fig. 1 Scheme of a heat-flux differential scanning calorimeter

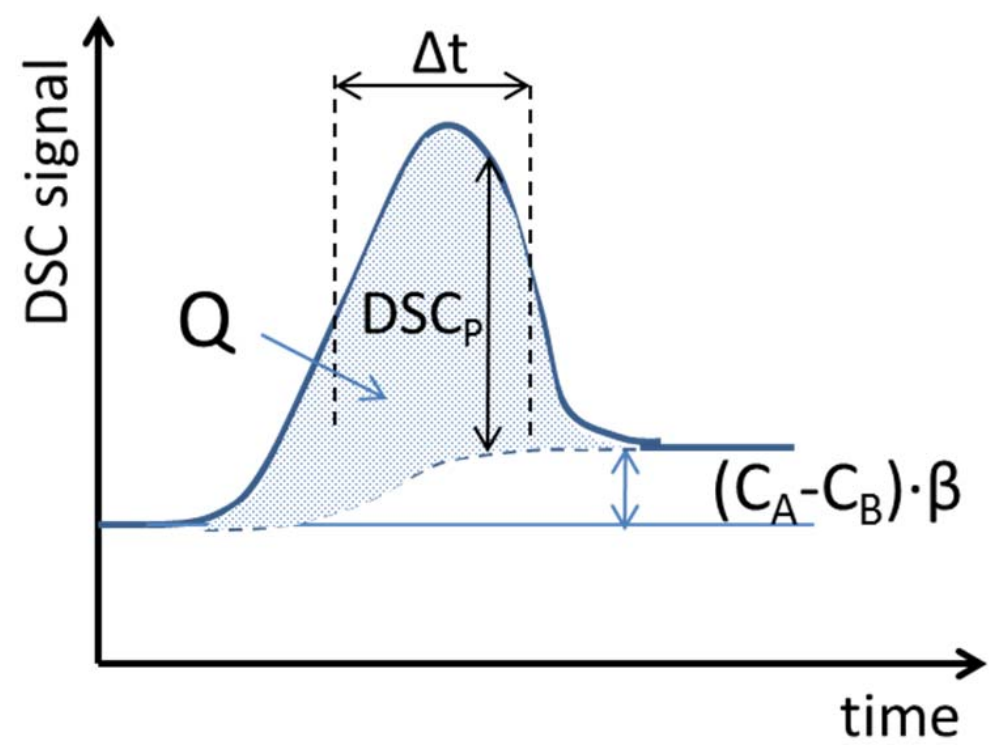

Fig. 2 The heat of reaction, Q, can be obtained from the DSC signal after subtraction of the baseline due to heat capacity variation that is proportional to the heating rate, $\beta$ 


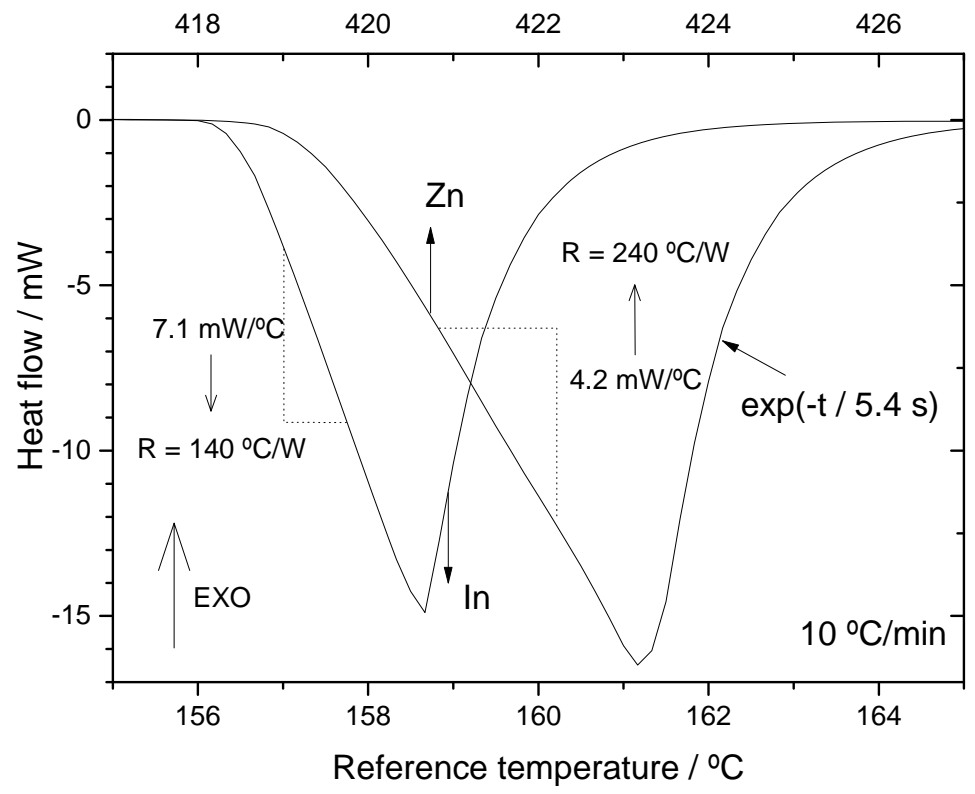

Fig. 3 Melting peaks of In and Zn references used to calibrate the DSC signal and to determine its thermal resistance $(R)$ and decay time constant $\left(\tau_{\text {SIGNAL }}\right)$

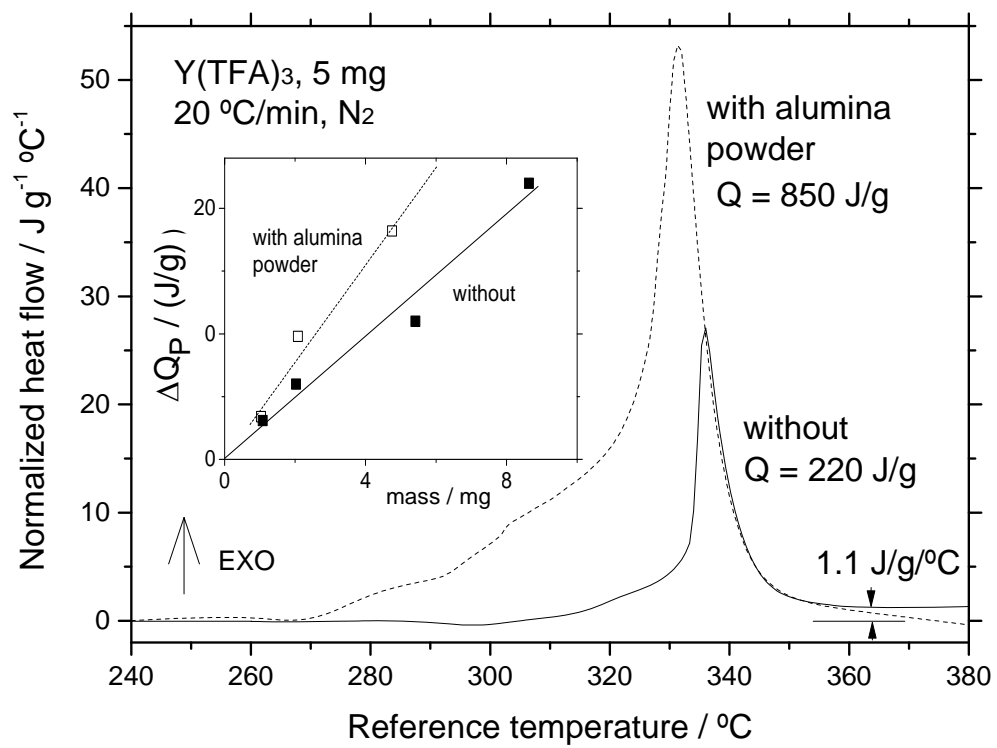

Fig. 4 DSC peaks of the decomposition of $\mathrm{Y}(\mathrm{TFA})_{3}$ in $\mathrm{N}_{2}$. Without cover, the volatiles are very overheated when they leave the sample pan and, consequently, the DSC peak is much less exothermic. Inset: estimated heat losses related to sample overheating 


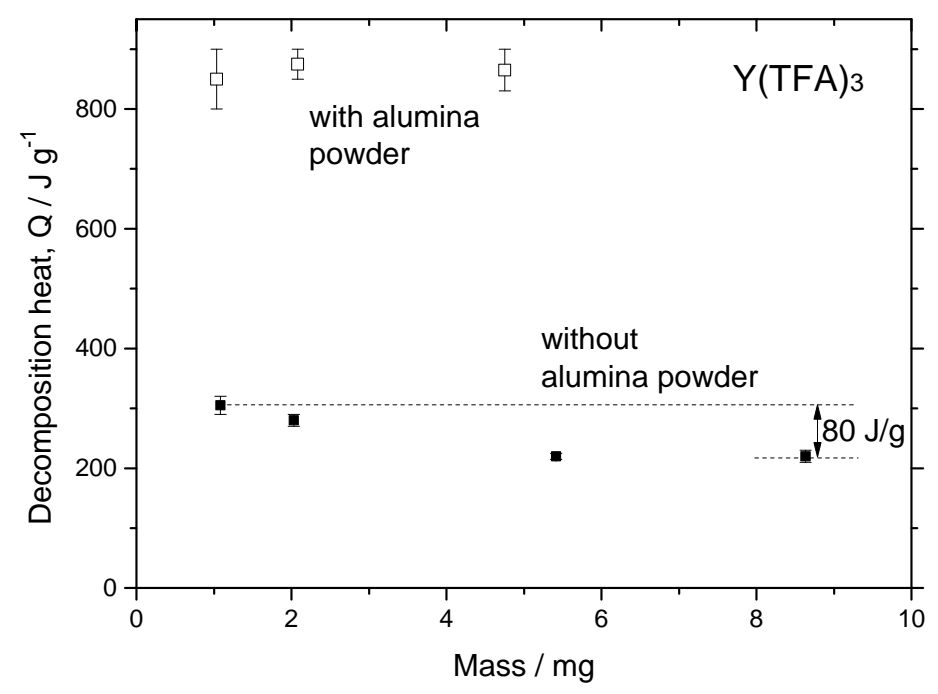

Fig. 5 Evolution of the decomposition heat of $\mathrm{Y}(\mathrm{TFA})_{3}$ with the initial sample mass

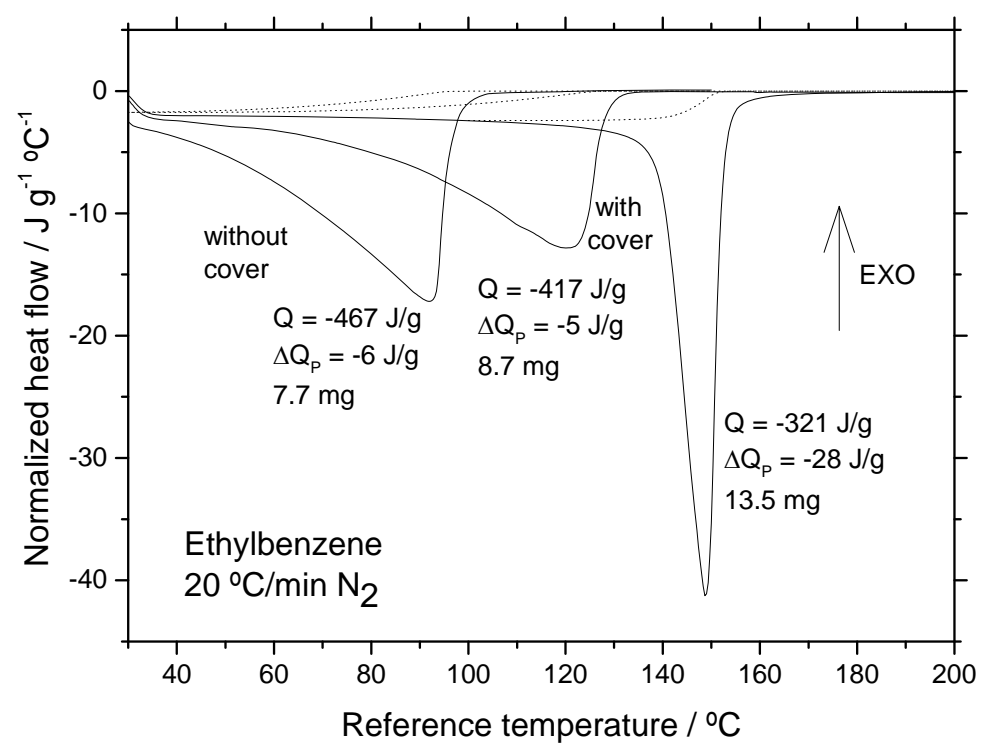

Fig. 6 DSC peaks measured during evaporation of ethylbenzene in aluminum pans. The sharpest peak was measured with the smallest pinhole on the cover. Dotted lines are the contribution of heat capacity. The values of $\Delta Q_{\mathrm{P}}$ have been calculated with Eq.14 


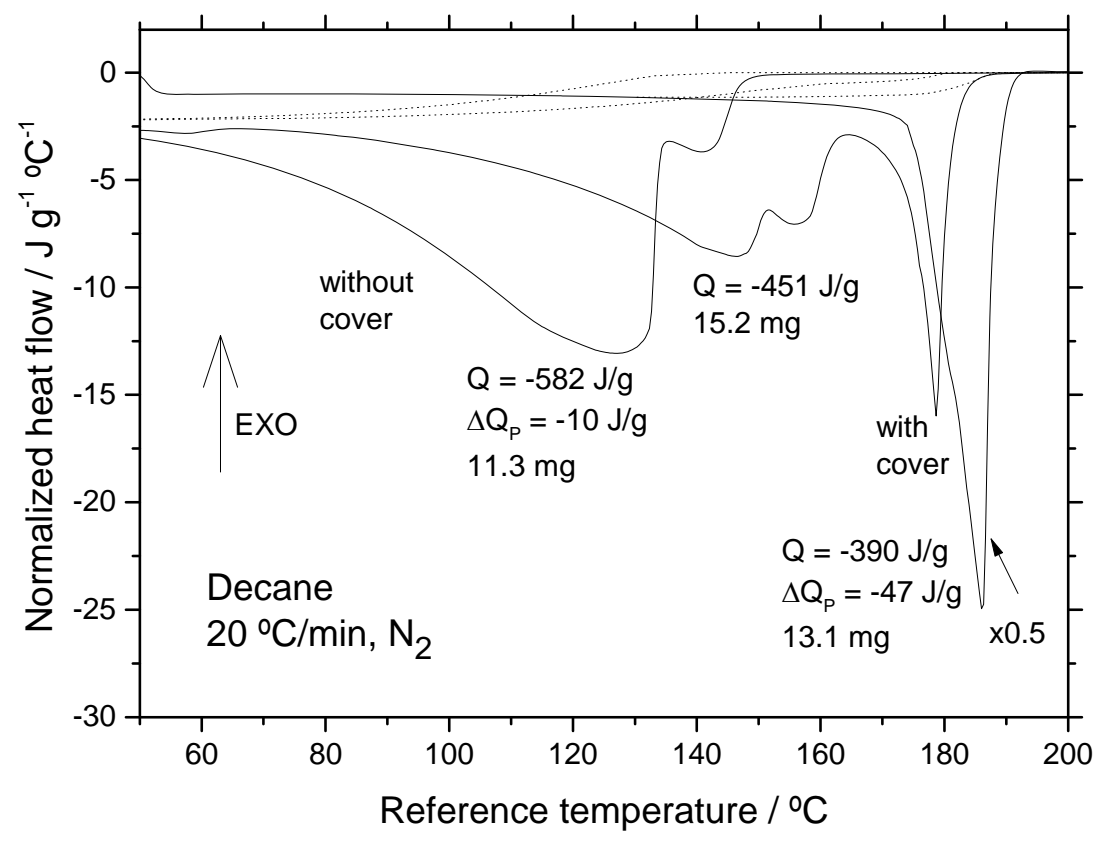

Fig. 7 DSC peaks measured during evaporation of decane in aluminum pans. The sharpest peak was measured with the smallest pinhole on the cover. Dotted lines are the heat capacity contribution. The values of $\Delta Q_{P}$ have been calculated with Eq.14 
Table 1 Thermal constants of several liquids: boiling point $\left(\mathrm{T}_{\mathrm{BOIL}}\right)$, specific heat capacity $\left(c_{p L}\right)$, latent heat of evaporation $\left(\mathrm{L}_{\mathrm{BOIL}}\right)$ at $\mathrm{T}_{\mathrm{BOIL}}$

\begin{tabular}{|l|l|l|l|l|}
\hline & \multicolumn{1}{|c|}{$\begin{array}{c}\mathrm{T}_{\mathrm{BOIL}} \\
/{ }^{\circ} \mathrm{C}\end{array}$} & $\begin{array}{c}\mathrm{c}_{\mathrm{pL}} \\
/ \mathrm{J} \mathrm{g}^{-1}{ }^{\circ} \mathrm{C}^{-1}\end{array}$ & $\begin{array}{c}\mathrm{L}_{\mathrm{BOIL}} \\
/ \mathrm{J} \mathrm{g}^{-1}\end{array}$ & $\begin{array}{c}\mathrm{c}_{\mathrm{pL}} / \mathrm{L}_{\mathrm{BOIL}} \\
/{ }^{\circ} \mathrm{C}^{-1}\end{array}$ \\
\hline water & 100 & 4.2 & 2257 & $1.8610^{-3}$ \\
\hline methanol & 65 & 2.5 & 1100 & $2.2710^{-3}$ \\
\hline ethanol & 79 & 2.5 & 846 & $2.9610^{-3}$ \\
\hline $\begin{array}{l}\text { ethylene } \\
\text { glycol }\end{array}$ & 197 & 2.4 & 800 & $3.0010^{-3}$ \\
\hline acetone & 133 & 2.15 & 518 & $4.1510^{-3}$ \\
\hline toluene & 111 & 1.72 & 351 & $4.9010^{-3}$ \\
\hline ethylbenzene & 136 & 1.75 & 335 & $5.2210^{-3}$ \\
\hline decane & 173 & 2.21 & 263 & $8.4010^{-3}$ \\
\hline dodecane & 216 & 2.21 & 256 & $8.6310^{-3}$ \\
\hline
\end{tabular}

